\title{
Effect of reducing agents on the structure of zinc oxide under microwave irradiation
}

\author{
Monica Debbarma · Soma Das $\cdot$ Mitali Saha
}

Received: 15 March 2013/Accepted: 18 April 2013/Published online: 28 April 2013

(c) Shanghai University and Springer-Verlag Berlin Heidelberg 2013

\begin{abstract}
Zinc oxide was synthesized from zinc sulphate using different reducing agents under microwave irradiation. The influence of sodium borohydride, hydrazine hydrate and urea on the shape and size of the products were investigated by scanning electron microscopy (SEM) and X-ray diffraction (XRD). SEM showed the nano-sized spherical and rectangular shaped structures in case of sodium borohydride and hydrazine hydrate, whereas micro-sized hexagonal structures were formed in case of urea under the same irradiation power. The reducing agents played an important role in forming the various structures. Thus different shapes and size of structures were produced by only varying the reducing agent, which had wide applications in various fields.
\end{abstract}

Keywords Zinc oxide - Microwave - Sodium borohydride $\cdot$ Hydrazine hydrate $\cdot$ Urea

\section{Introduction}

Oxides of transition metal have become one of the most interesting focus in many areas, such as chemistry, physics and material sciences [1]. Among which, $\mathrm{ZnO}$ has wide applications in the areas such as solar cells [2-4], catalysis [5, 6], sensors [7], laser diodes [8] and varistors [5, 9]. Various techniques had been employed for the synthesis of the nano/micro structured $\mathrm{ZnO}$ such as sol-gel process [10], homogeneous precipitation [5], thermal decomposition [11], microwave heating [12], conventional hydrothermal

M. Debbarma · S. Das $(\bowtie) \cdot$ M. Saha

Department of Chemistry, National Institute of Technology, Agartala 799055, Tripura, India

e-mail: mitalisah@gmail.com; somachem17@gmail.com
[13-15], etc. Compared with the conventional heating methods, the microwave heating has many advantages of developing small particles of metal oxides with nano or micro sizes and better purity in short time [16-19]. In this paper, microwave heating has been utilized for the preparation of the zinc oxide in the presence of different reducing agents such as sodium borohydride, hydrazine hydrate and urea. The effect of the reducing agents on the size and shape of the formed products has been studied by scanning electron microscopy (SEM) and X-ray diffraction (XRD). It was found that different structure was obtained using the different reducing agents under the same starting material, ratio and irradiation power.

\section{Experimental}

2.1 Synthesis of zinc oxide from zinc sulphate and sodium borohydride

The zinc oxide was prepared by stirring 1:2 ratio aqueous solutions of zinc sulphate and sodium borohydride in at $60-80{ }^{\circ} \mathrm{C}$, which produced a clear solution. Then it was heated in a microwave oven at $360 \mathrm{~W}$, which produced a white precipitate after 2-3 min. The precipitate was centrifuged, washed with distilled water and crystallized with methanol. Finally the precipitate was kept for drying at $100{ }^{\circ} \mathrm{C}$ for $3-4 \mathrm{~h}$.

2.2 Synthesis of zinc oxide from zinc sulphate and hydrazine hydrate

The zinc oxide was prepared by stirring 1:2 ratio aqueous solution of zinc sulphate and hydrazine hydrate at $60-80{ }^{\circ} \mathrm{C}$. After mixing the solutions, a slight amount of 


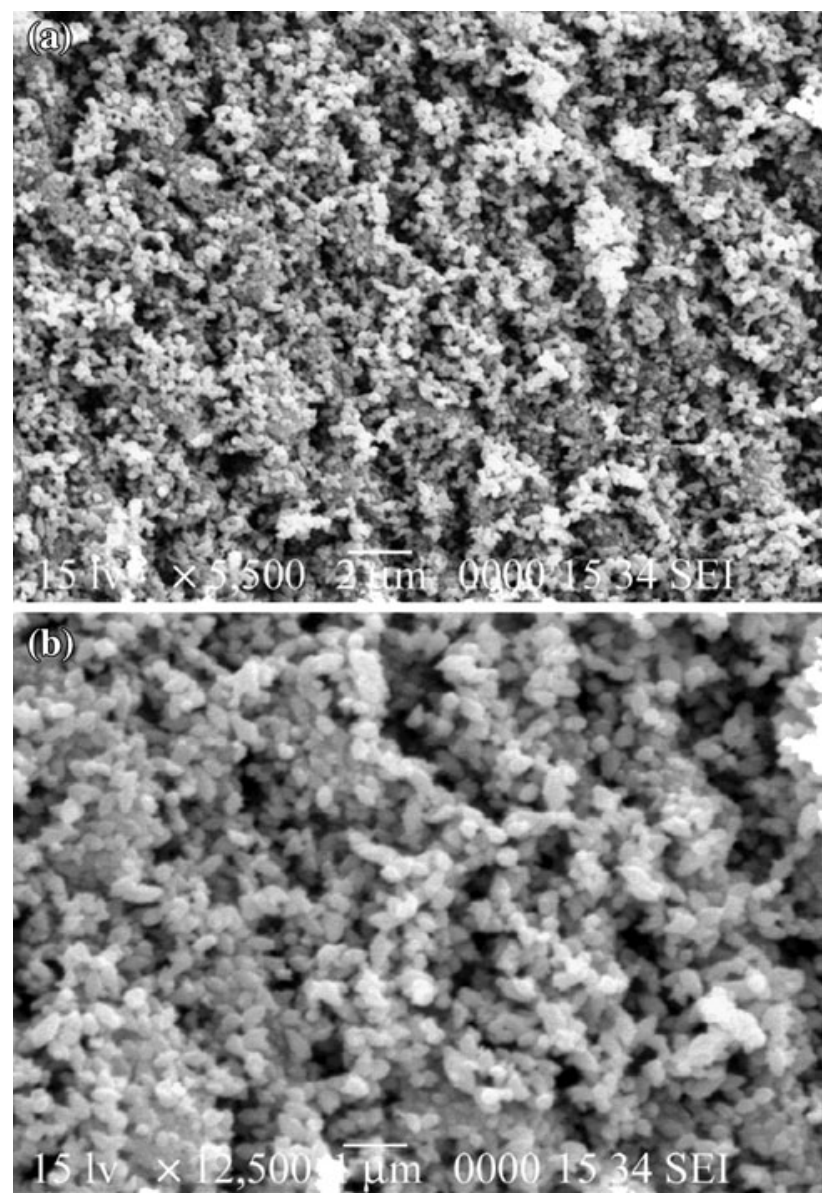

Fig. 1 SEM of the spherical zinc oxide with sodium borohydride

white precipitate was observed. Then it was heated in microwave oven under the same irradiation power, which produced thick precipitate in 5-6 min. The precipitate was centrifuged, washed with distilled water and crystallized with methanol. Finally it was kept for drying at $100{ }^{\circ} \mathrm{C}$ for 3-4 h.

\subsection{Synthesis of zinc oxide from zinc sulphate and urea}

Zinc sulphate and urea taking in the same 1:2 ratio was heated under the same conditions. After $10 \mathrm{~min}$, a thick precipitate was obtained. Then it was centrifuged, washed, crystallized, and dried for 3-4 h.

\section{Results and discussions}

The preparation of $\mathrm{ZnO}$ was studied using zinc sulphate and three different types of reducing agents under microwave conditions at the same irradiation power of $360 \mathrm{~W}$. Up to $180 \mathrm{~W}$, the yield was found to be very poor in all the cases. The SEM micrographs of $\mathrm{ZnO}$ nanoparticles using different reducing agents were shown in Figs. 1-3.
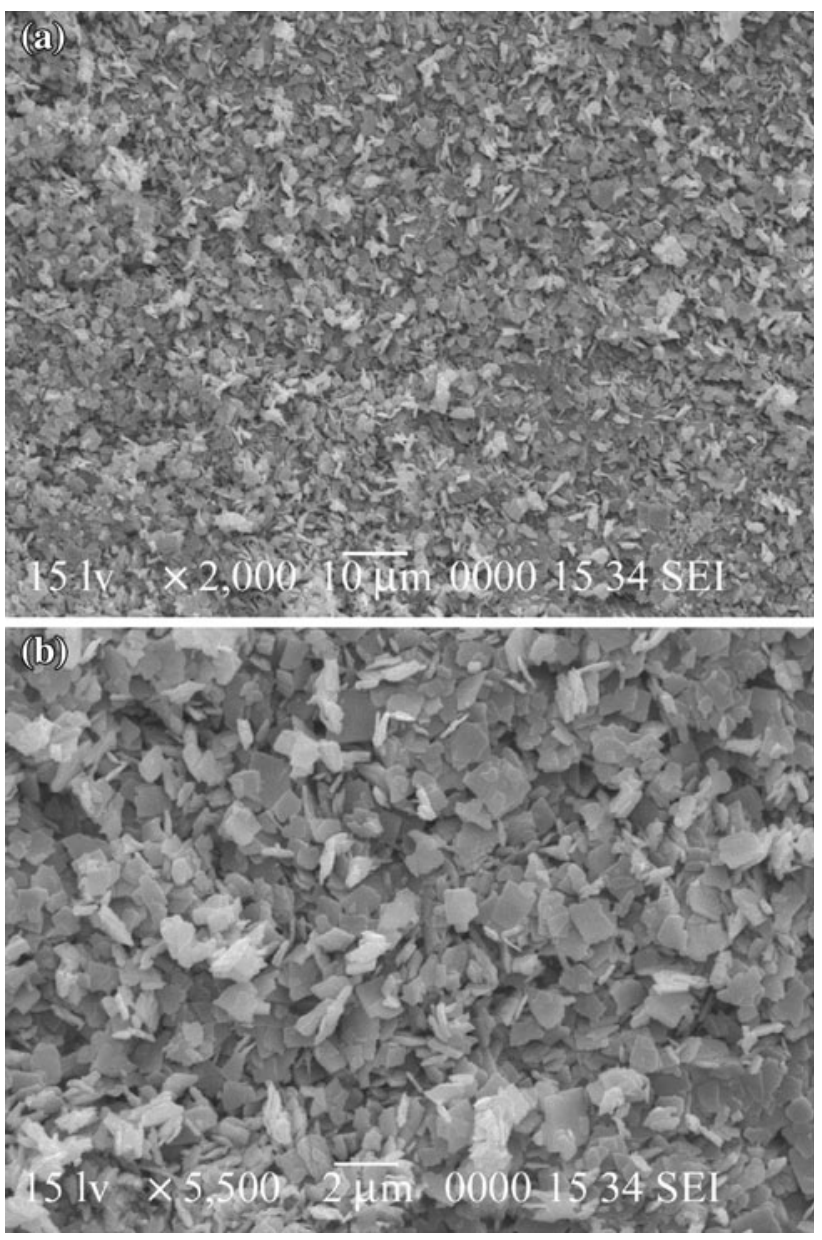

Fig. 2 SEM of the rectangular shaped zinc oxide with hydrazine hydrate

Figure 1 showed that $\mathrm{ZnO}$ possessed the spherical shape when sodium borohydride was used. Figure 2 showed the rectangular shaped nanostructures of $\mathrm{ZnO}$ in the presence of hydrazine hydrate. Sodium borohydride was used for the first time for the synthesis of zinc oxide under the microwave irradiation. It was interesting to observe that urea as an organic base produced the micro-sized (see Fig. 3) hexagonal shape structures with zinc sulphate. It could be concluded that different shapes and sizes varying from micron to nano-size of $\mathrm{ZnO}$ could be obtained using the different reducing agents under the same starting material and irradiation power. Compared to other heating methods, microwave heating was easy to produce the pure products with good yields.

Figure 4 showed the very sharp peaks in XRD pattern of $\mathrm{ZnO}$ nanostructures with sodium borohydride. The XRD pattern indicated the presence of peaks at $2 \theta$ values of $31.65^{\circ}, 34.35^{\circ}, 36.15^{\circ}, 47.45^{\circ}, 56.4^{\circ}, 62.75^{\circ}$, and $67.7^{\circ}$ corresponds to (100), (002), (101), (102), (110), (103) and (200) planes of $\mathrm{ZnO}$ respectively. Similar peaks were also observed in the case of hydrazine hydrate (see Fig. 5). The 

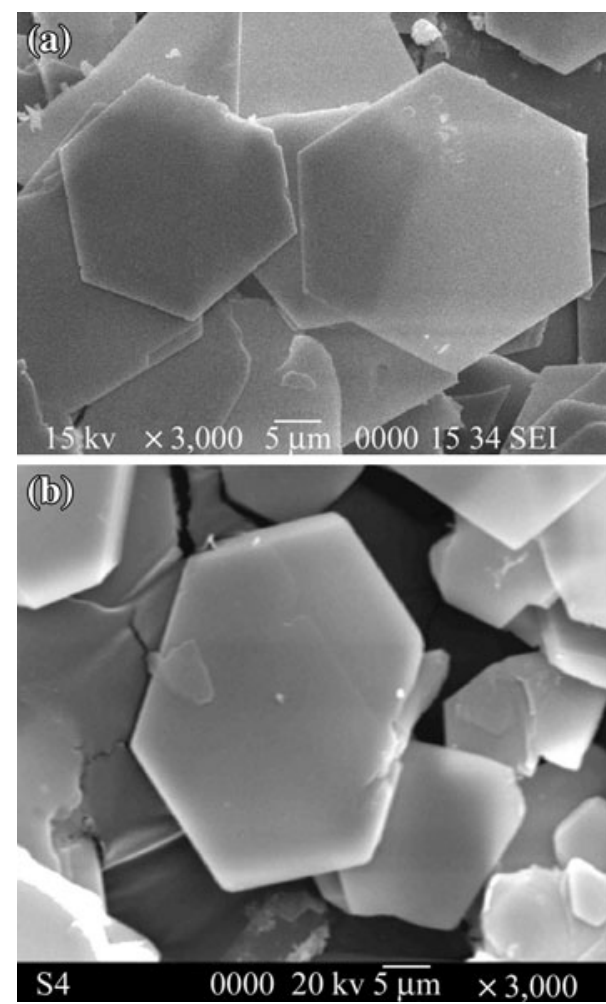

Fig. 3 SEM of the hexagonal zinc oxide with urea

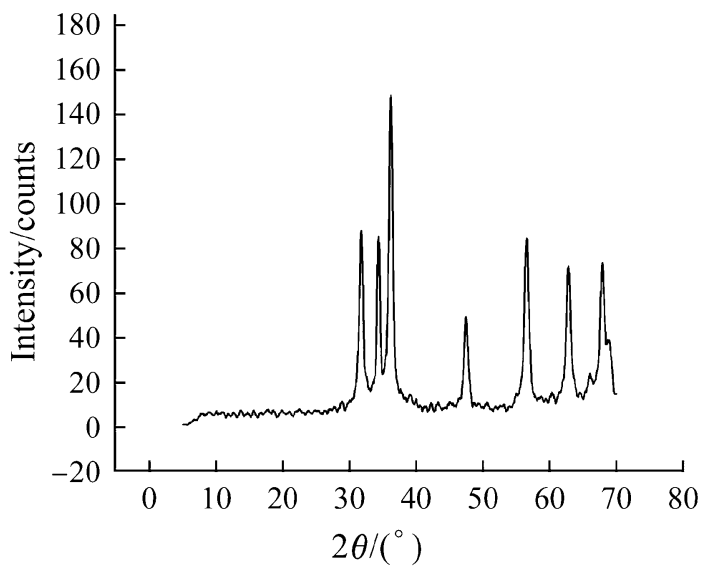

Fig. 4 XRD of the spherical zinc oxide with sodium borohydride

strongest peak at $2 \theta=36.15^{\circ}$ belongs to the (101) plane of the products. In Fig. 6, the peaks were in the different position showing the formation of different structures in the case of urea, which further confirmed the formation of micro-sized hexagonal shapes.

\section{Conclusions}

Different structures of zinc oxide were successfully synthesized using the easily available domestic microwave

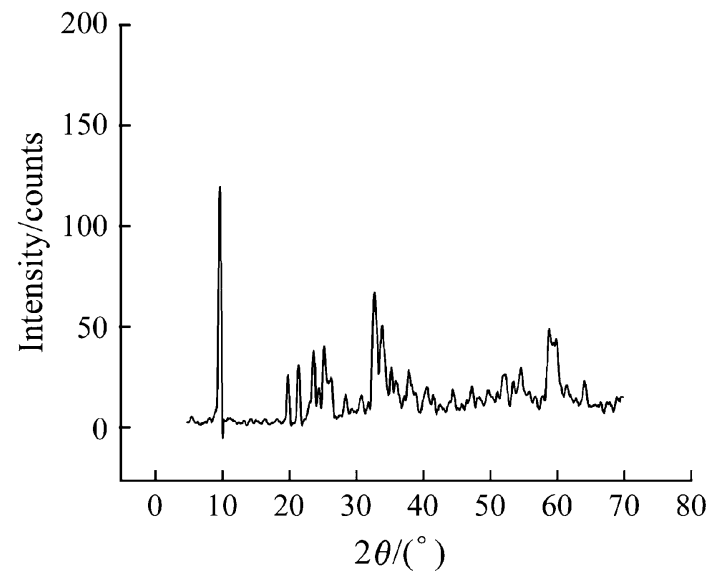

Fig. 5 XRD of the rectangular shaped zinc oxide with hydrazine hydrate

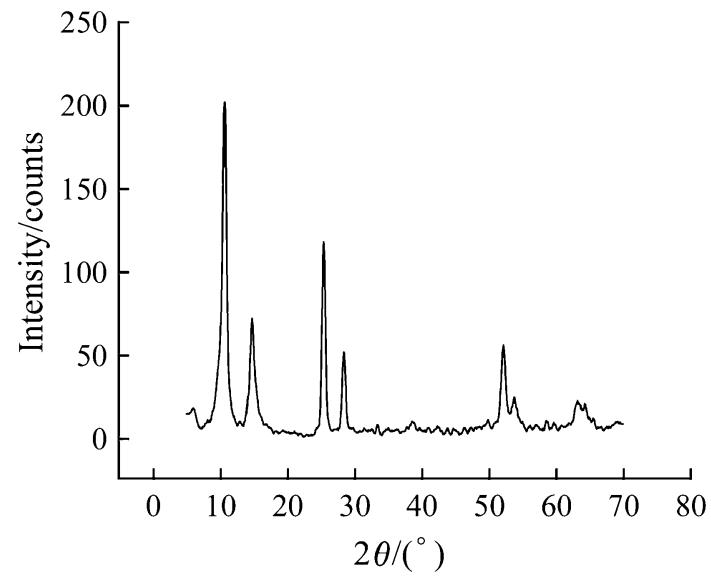

Fig. $6 \mathrm{XRD}$ of the hexagonal zinc oxide with urea

oven. Compared to the other conventional heating methods, microwave heating was found to be economic and could produce good yields of products. The reducing agents play an important role during the synthesis process. The SEM confirmed the formation of the different structures of $\mathrm{ZnO}$ with the spherical, rectangular and hexagonal shapes. Thus different shapes and sized of micro- and nanomaterials can be prepared by varying these reducing agents, which will have a wide range of applications in various fields.

Acknowledgments Authors express their gratitude to the Director, National Institute of Technology, Agartala to allow for publishing the results. Financial assistance from CPRI, Bangalore and SEM analysis from Tezpur University are greatly acknowledged.

\section{References}

1. Bitenc M, Orel ZC (2009) Synthesis and characterization of crystalline hexagonal bipods of zinc oxide. Mater Res Bull 44:381-387 
2. Peiro AM, Ravirajan P, Govender K et al (2006) Hybrid polymer/ metal oxide solar cells based on $\mathrm{ZnO}$ columnar structures. J Mater Chem 16:2088-2096

3. Srikanth CK, Jeevanandam P (2009) Effect of anion on the homogeneous precipitation of precursors and their thermal decomposition to zinc oxide. J Alloy Compd 486(1-2):677-684

4. Ada K, Goekgoez M, Oenal M et al (2008) Preparation and characterization of a $\mathrm{ZnO}$ powder with the hexagonal plate particles. Powder Technol 181:285-291

5. Cheng C, Liu B, Yang $\mathrm{H}$ et al (2009) Hierarchical assembly of $\mathrm{ZnO}$ nanostructures on $\mathrm{SnO}_{2}$ backbone nanowires: low-temperature hydrothermal preparation and optical properties. ACS Nano 3:3069-3076

6. Baruah S, Dutta J (2009) Hydrothermal growth of $\mathrm{ZnO}$ nanostructures. Sci Technol Adv Mater 10(1):013001. doi: 10.1088/1468-6996/10/1/013001

7. Ram SDG, Kulandainathan MA, Ravi G (2010) On the study of $\mathrm{pH}$ effects in the microwave enhanced rapid synthesis of nanoZnO. Appl Phys A 99:197-203

8. Lima SAM, Cremona M, Davolos MR et al (2007) Electroluminescence of zinc oxide thin-films prepared via polymeric precursor and via sol-gel methods. Thin Solid Films 516:165-169

9. Music S, Popovic S, Maljkovic M et al (2002) Influence of synthesis procedure on the formation and properties of zinc oxide. J Alloy Compd 347:324-332

10. Peiro AM, Domingo C, Peral J et al (2005) Nanostructured zinc oxide films grown from microwave activated aqueous solutions. Thin Solid Films 483:79-83
11. Jiang JY, Li YF, Tan SW et al (2010) Synthesis of zinc oxide nanotetrapods by a novel fast microemulsion-based hydrothermal method. Mater Lett 64:2191-2193

12. Mo M, Yu JC, Zhang LZ et al (2005) Self-assembly of ZnO nanorods and nanosheets into hollow microhemispheres and microspheres. Adv Mater 17:756-760

13. Wei A, Sun XW, Xu CX et al (2006) Growth mechanism of tubular $\mathrm{ZnO}$ formed in aqueous solution. Nanotechnology $17: 1740-1744$

14. Chen DR, Jiao XL, Cheng G (1999) Hydrothermal synthesis of zinc oxide powders with different morphologies. Solid State Commun 113:363-366

15. Lu CH, Yeh CH (2000) Influence of hydrothermal conditions on the morphology and particle size of zinc oxide powder. Ceram Int 26:351-357

16. He Y, Yang B, Cheng G (2004) On the oxidative coupling of methane with carbon dioxide over $\mathrm{CeO} / \mathrm{ZnO}$ nanocatalysts. Catal Today 98:595-600

17. Glaspell G, Dutta P, Manivannan A (2005) A room-temperature and microwave synthesis of $\mathrm{M}$-doped $\mathrm{ZnO}(\mathrm{M}=\mathrm{Co}, \mathrm{Cr}, \mathrm{Fe}, \mathrm{Mn}$ \& Ni). J Cluster Sci 16(4):523-526

18. Hamedani NF, Farzaneh F (2006) Synthesis of ZnO nanocrystals with hexagonal (wurtzite) structure in water using microwave irradiation. J Sci Islam Repub Iran 17(3):231-234

19. Krishnakumar T, Pinna N, Kumari KP et al (2008) Microwaveassisted synthesis and characterization of tin oxide nanoparticles. Mater Lett 62(19):3437-3440 